\title{
Robert Darnton. Acceso Abierto y otras reflexiones. Bogotá: Universidad de los Andes, 2017.
}

DOI: http://dx.doi.org/10.15648/hc.32.2018.8

El presente libro del historiador estadounidense Robert Darnton, es una compilación precisa de sus ideas, reflexiones y posturas sobre la evolución del libro, su influencia en las sociedades occidentales, y su relación con los soportes electrónicos que cada vez más ganan un espacio considerable en nuestras vidas. El libro está editado por la Universidad de los Andes, en su colección Séneca, en un esfuerzo por difundir las obras de historiadores reconocidos en el panorama académico colombiano. El libro está compuesto por cinco capítulos, de los cuales, los primeros cuatro son ensayos y conferencias dictadas en distintos recintos académicos, siendo el último una entrevista realizada por el periodista venezolano Boris Muñoz al autor.

Darnton es especialista en la historia del libro, sobre todo es experto en el siglo XVIII francés, las influencias del libro en la sociedad del antiguo régimen en Francia, y cómo esto contribuyó a la aparición de un público lector. Sus múltiples investigaciones sobre el poder del libro, sus usos, y sus alcances, le han asignado un reconocimiento importante en el ámbito de la historiografía de la historia cultural. Además, actualmente dirige el proyecto de la Biblioteca Digital Pública de Estados Unidos (DPLA, por sus siglas en inglés) que aspira a ser un lugar de referencia obligatoria para las búsquedas de libros digitales en Estados Unidos. Asimismo, ayudar a la democratización de la difusión del libro digital en oposición al monopolio que pretende implantar Google con su proyecto Google Books Search.

El primer capítulo llamado: Digitalizar, democratizar: las bibliotecas y el futuro de los libros, es una transcripción de una conferencia que dictó en el 2015 en la Universidad de los Andes. En ella, Darnton nos expone cómo el mundo digital, paradójicamente, ha influido en el crecimiento de 
los libros y las bibliotecas públicas. Lejos de estar cerca el final del libro físico, tal cual como lo conocemos hoy día, las tiradas de libros aumentan cada año de manera exponencial. Las bibliotecas son parte esencial de dicho proceso, puesto que, gracias a ellas, el conocimiento se ha expandido a lo largo de la historia.

Al crecer los repositorios de las bibliotecas, viene con ello el problema de cómo democratizar la difusión y recepción de los textos. El problema principal que atraviesan las bibliotecas públicas en Estados Unidos, y en gran parte del mundo occidental, son los altos costes de las publicaciones académicas que, han minado el presupuesto de estos recintos. Darnton argumenta desde su experiencia anterior de director de la biblioteca de Harvard, que se debe primar ante todo el libre acceso a la información, y colocar límites a las editoriales académicas en el alto costo de sus publicaciones.

El segundo capítulo: Google y el futuro de los libros. Darnton nos conduce por la problemática del monopolio editorial de grandes empresas como, Elsevier, y últimamente Google. Google ha venido digitalizando millones de libros en un proyecto que se conoce como Google Book Search, en su idea, está la digitalización de todos los libros del mundo y ponerlos al alcance de cada persona que tenga una conexión a Internet. Por muy utópico que parezca, es posible gracias al poderío económico y humano que Google ha alcanzado a lo largo de los años. El problema que subsiste es, de qué manera esta digitalización afectará la vida de las bibliotecas en cada país y de qué forma Google dispondrá los libros en la red. Además, el copyright es la barrera actual para las digitalizaciones, por lo cual las negociaciones con los autores serán de vital importancia a la hora de ponerlos en la red.

Darnton apelando a su experiencia investigativa, nos muestra cómo la Ilustración sirve de referencia a pesar de estar separada por casi 250 años. El conocimiento al alcance de todos era una de las máximas de la Ilustración, pero se ha demostrado que, en realidad, entraban a ese nicho solo quienes tuvieran el poder suficiente y las conexiones más fuertes en un mundo mayoritariamente analfabeta. Lo mismo sucede actualmente con el pro- 
yecto de Google, Darnton aboga por un equilibrio entre el comercio y el libre acceso a la información, cuestión que se puede colocar en entredicho si prima más la rentabilidad por encima del libre acceso al conocimiento. Problemática que viene en ascendencia debido al aumento del precio de suscripción de las revistas especializadas, haciendo mella en el presupuesto de las bibliotecas y de paso, mermando la compra de monografías por parte de estas.

En el tercer capítulo: El panorama de la información, Darnton sintetiza cuatro grandes cambios fundamentales en el escenario de la información mundial, a saber: la escritura, la aparición del códice, los caracteres móviles de la imprenta de Gutenberg, y la comunicación electrónica. Por más que se abogue que actualmente estamos inmersos en una era de la información, Darnton sostiene que "cada época fue una era de la información, cada una a su manera, y que la información siempre ha sido inestable"1.

El autor nos hace un recuento por la historia para demostrar que, los múltiples problemas de derechos de autor, piratería, y lo que se ha hecho llamar "la sociedad de la información", no es cuestión solo de este siglo XXI, "puede servir como correctivo ante la creencia de que la aceleración del cambio tecnológico nos ha catapultado hacia una nueva era... yo diría que la tecnología de la información nos ha obligado a repensar la noción misma de información" ${ }^{2}$. El problema actual sobre la fiabilidad de la información la contrasta con ejemplos puntuales, como las falsas noticias que corrían por Inglaterra durante la independencia de los Estados Unidos, y los libelos infamatorios contra el rey de Francia en el antiguo régimen.

Los últimos capítulos del libro son un ensayo publicado bajo el nombre de: Libros electrónicos y libros viejos, y una entrevista realizada por el periodista venezolano Boris Muñoz, llamado, El libro: fabulosa máquina. Los cuales están íntimamente relacionados por una misma línea de exposición: la permanencia, el poder, y la importancia del libro en nuestra socie-

1 Robert Darnton. Acceso abierto y otras reflexiones. (Bogotá: Universidad de los Andes. Colección Seneca. 2017), 48.

2 Robert Darnton. Acceso abierto y otras..., 57. 
dad. Darnton se enfoca en demostrar magistralmente que, no ha habido una coyuntura real capaz de sostener la desaparición del libro como lo pronosticaron ciertos académicos en décadas anteriores (McLuhan). Nos muestra cómo se pasó de un entusiasmo utópico por la aparición del libro electrónico, a una tendencia de pragmatismo, en el cual ninguna opción excluye a la otra; más que una ruptura, lo que existe es una relación entre el libro impreso y el electrónico, "que servirá como suplemento, no sustituto, de la gran máquina de Gutenberg”’3.

Acceso abierto y otras reflexiones es un libro que nos sirve de mapa general para comprender, de manera concisa y crítica, los pormenores de esta "sociedad de la información”. Los retos, problemas, la anatomía del mundo editorial y la influencia de grandes empresas como Google en la difusión del conocimiento actual. Y cómo las bibliotecas de cada ciudad, así como las universitarias, tienen el deber y el poder de ir acompañando las transformaciones que se den al paso sin por ello perder preponderancia en la conformación y difusión del conocimiento.

\section{Bryan Alcázar Marenco}

Historiador de la Universidad del Atlántico (Colombia) bryanalcazar45@gmail.com 